\title{
O paradigma indiciário para análise de narrativas
}

\section{The evidentiary paradigm for analysis of narratives}

\author{
Everaldo Gomes Leandro* \\ Cármen Lúcia Brancaglion Passos ${ }^{* *}$
}

\begin{abstract}
RESUMO
Neste artigo objetiva-se apresentar contribuições do paradigma indiciário para a análise de narrativas em pesquisas do campo da Educação. $\mathrm{O}$ paradigma indiciário, estudado e utilizado pelo historiador italiano Carlo Ginzburg, possibilita interpretar a realidade, algumas vezes opaca, em busca de características menos vistosas, de indícios que permitam decifrá-la e compreendê-la. Porém, constatou-se que há uma utilização restrita do paradigma indiciário no Brasil, e por esse motivo surgiram perguntas: que contribuições o paradigma indiciário traz para a análise de narrativas? E que elementos considerar, à procura de indícios? Esta pesquisa é de cunho teórico e constitui-se como um recorte da tese de doutorado do primeiro autor.

Palavras-chave: Paradigma indiciário. Análise de narrativas. Indícios narrativos. Pesquisa em Educação.
\end{abstract}

\begin{abstract}
This article aims to present contributions from the evidentiary paradigm for the analysis of narratives in research in the field of Education. The evidentiary paradigm studied and used by the Italian historian Carlo Ginzburg, makes it possible to interpret the reality, sometimes opaque, in search of less showy characteristics, of clues that make it possible to decipher and understand it.
\end{abstract}

* Instituto Federal de Educação, Ciência e Tecnologia de São Paulo. Campus Registro, São Paulo, Brasil. E-mail: everaldo.gomes@ifsp.edu.br - https://orcid.org/0000-0002-7226-1504

${ }^{* *}$ Universidade Federal de São Carlos. São Carlos, São Paulo, Brasil. E-mail: carmenpassos@ gmail.com - http://orcid.org/0000-0002-5501-3584 
However, it was found that there is restricted use of the evidentiary paradigm in Brazil, and for this reason, a question arose: what contributions does the evidentiary paradigm bring to the analysis of narratives, and what elements to consider in search of clues? This research is theoretical and constitutes an excerpt of the doctoral thesis of the first author.

Keywords: Evidentiary paradigm. Analysis of narrative. Narrative clues. Education Research.

\section{Introdução}

A experiência humana pode ser, de alguma maneira, reconstruída a partir de uma narrativa. Esse tipo especial de gênero do discurso (BOLÍVAR; DOMINGO; FERNÁNDEZ, 2001) é escolhido para investigar, atualmente, histórias de vida, práticas, visões de mundo, sentidos e significados. Na área da Educação, as narrativas colocam em evidência os discursos de sujeitos que, às vezes, estão à margem de políticas públicas, de currículos, de bases e/ou normativas. Por outro lado, há uma polissemia no uso da palavra "narrativa". A escrita do professor, as narrativas (auto)biográficas, as narrativas da experiência, as histórias de vida, os memoriais e as narrativas de aulas são alguns dos seus usos correntes (NACARATO; PASSOS; SILVA, 2014, p. 702).

Nesse cenário, a análise de narrativas torna-se, para o pesquisador, um desafio. Perguntas do tipo, como analisar uma narrativa? que elementos levar em consideração durante a análise?, passam a existir. Esse desafio surgiu para o primeiro autor deste artigo no desenvolvimento de sua pesquisa de doutorado. À procura de superar tal desafio, percebi ${ }^{1}$ no paradigma indiciário, na perspectiva proposta pelo historiador italiano Carlo Ginzburg, contribuições para a análise de narrativas.

Todavia, como Leonardi e Aguiar (2010), observei que há uma utilização restrita do paradigma indiciário no Brasil em artigos, teses e dissertações; que predominam citações do capítulo "Sinais: Raízes de um paradigma indiciário", do livro "Mitos, emblemas, sinais: morfologia e história" (GINZBURG, 1989),

1 Neste texto, assim como na tese, a primeira pessoa do singular foi a predominante. O eu pressupõe o outro. Aqui a multiplicidade das vozes se encontra no eu e cria um texto polifônico (GIOVANI; SOUZA, 2014). Há o eu-orientadora, o eu-teóricos, o eu-membros da banca, entre outros. Minha palavra é forjada pela palavra do outro, de muitos outros (BAKHTIN, 1997). 
em detrimento das outras produções de Carlo Ginzburg, como ocorre nas pesquisas de Cabrera (2012), Pimentel e Montenegro (2007) e Gomes (2017), por exemplo; que se utilizam dispositivos de investigação, a exemplo de alguns tipos de entrevistas e questionários, os quais parecem não dialogar com o paradigma, pela própria maneira como tais dispositivos são construídos e dificultam a percepção dos indícios - elementos centrais do paradigma; e que não é clara a utilização de conceitos associados ao paradigma indiciário.

Se, por um lado, percebi, na leitura das pesquisas de Ginzburg $(1989,1990$, 1999, 2001, 2004, 2006, 2007, 2010, 2012, 2014), contribuições para a análise de narrativas, por outro, não encontrei pesquisas brasileiras (principalmente teses e dissertações) que me indicassem caminhos para empregar o paradigma indiciário em minha pesquisa ${ }^{2}$. A partir dessa motivação, me perguntei: que contribuições o paradigma indiciário traz para a análise de narrativas, e que elementos considerar, à procura de indícios?

Para responder tais questionamentos, apresento neste artigo contribuições do paradigma indiciário para a análise de narrativas em pesquisas do campo da Educação. Esta pesquisa é de cunho teórico, e o texto está estruturado no intuito de, em um primeiro momento, compreender a obra de "Carlo Ginzburg, o paradigma indiciário e seus pressupostos" e, em um segundo, apresentar "Contribuições do paradigma para a análise de narrativas: a procura de indícios".

\section{Carlo Ginzburg, o paradigma indiciário e seus pressupostos}

Carlo Ginzburg é um historiador italiano. Nasceu em Turim em 1939, filho dos judeus Leone e Natalia Ginzburg. O pai foi professor de literatura russa, e a mãe, romancista. No seio de uma família de intelectuais, compreendeu desde cedo a "dimensão literária no trabalho do historiador" (GINZBURG, 1990, p. 255). Essa compreensão repercutiu posteriormente em seu modo de fazer história e de reconstruir e criar suas próprias narrativas.

2 Um levantamento das pesquisas ocorreu no Banco de Teses e Dissertações da Coordenação de Aperfeiçoamento de Pessoal de Nível Superior (CAPES) e da Biblioteca Digital Brasileira de Teses e Dissertações (BDTD) em dois momentos: um no ano de 2017 e outro em 2020, com os seguintes termos: "paradigma indiciário"; "paradigma indiciário e narrativas"; "paradigma indiciário e Educação Matemática". Além disso, diferentes periódicos e artigos que utilizaram o paradigma indiciário em diferentes áreas de pesquisa foram consultados. 
Ginzburg, um dos fundadores da micro-história, desenvolveu esse gênero historiográfico em que se faz o "recorte de objeto em escala microscópica, mas explorando tal objeto à exaustão, de modo a desvendar o universo de uma sociedade para além do próprio protagonista do estudo" (COELHO, 2014, p. 3).

O livro "O queijo e os vermes" é um dos exemplos mais conhecidos de um recorte explorado à exaustão por Ginzburg (2006). A narrativa ali construída centra-se na vida de um único sujeito: Domenico Scandella, um moleiro italiano que viveu no século XVI, mais conhecido como Menocchio. A farta documentação sobre o processo sofrido por Menocchio pela Inquisição Católica possibilitou que Ginzburg remontasse à cultura popular em uma Europa préindustrial, marcada pela repressão nos países católicos e que levou diversas pessoas a serem consideradas bruxas, curandeiras ou benandanti (expressão do distrito de Friuli na Itália para designar os feiticeiros do bem que combatiam, com ramos de erva-doce, os feiticeiros maus, adoradores do diabo).

Ginzburg (2006, p. 9) segue os rastros deixados pelos documentos sobre Menocchio e, desse modo, tem condições de saber "quais eram suas leituras e discussões, pensamentos e sentimentos: temores, esperanças, ironias, raivas, desesperos". A narrativa sobre Menocchio é construída no pressuposto da dialética entre o macro e o micro, sem que se esqueça de que posição se vê. No caso de "O queijo e os vermes", a posição que se vê é de um moleiro, do "mundo visto por um moleiro" (GINZBURG, 1999).

As micro-histórias construídas e investigadas por Ginzburg, como a presente em "O queijo e os vermes", são possíveis a partir do modelo epistemológico para interpretação, denominado de "paradigma indiciário". Em sentido lato, pode-se dizer que o paradigma indiciário não se baseia nas características mais vistosas da situação pesquisada, porém atenta em indícios, às vezes imperceptíveis, em sintomas, em signos pictóricos, em pormenores, em dados marginais e em pistas (GINZBURG, 1989).

O paradigma indiciário emergiu nas ciências humanas por volta do século XIX. Porém, seu surgimento remonta aos primeiros homens e está relacionado com o próprio desenvolvimento da narração: "o caçador teria sido o primeiro a 'narrar uma história' porque era o único capaz de ler, nas pistas mudas (se não imperceptíveis) deixadas pela presa, uma série coerente de eventos" (GINZBURG, 1989, p. 152). A partir de dados aparentemente negligenciáveis, os seres humanos remontam e contam aos outros humanos, pela narração, uma realidade complexa que não vivenciaram diretamente (pegadas dão indícios de que um animal passou pelo local, por exemplo).

O caçador, argumenta Ginzburg (2004), utilizava-se do paradigma indiciário como um modelo venatório (projetado para a compreensão do passado) para afirmar: "alguém passou por ali", enquanto os povos da Mesopotâmia o 
utilizavam como um modelo divinatório - quando o paradigma era projetado para a compreensão do futuro ${ }^{3}$.

O paradigma indiciário, como modelo divinatório, está presente na epopeia do Dilúvio da religião suméria, por exemplo. Essa epopeia, que posteriormente serviu de base ao Velho Testamento, narra que "cheios de inveja do homem, os deuses resolveram destruir completamente a raça dos mortais, afogando-os. Um deles, no entanto, revelou o segredo a um habitante da terra [...]" (BURNS, 1972 , p. 82, grifo meu). As revelações, a partir dos indícios da chegada de um dilúvio e da necessidade de construção de uma arca, auxiliaram a compreender o futuro, no que se refere aos períodos de chuva e às inundações dos terrenos. Assim, o modelo divinatório está presente tanto nas religiões quanto na cultura dos povos da Mesopotâmia.

Presentemente, Ginzburg (1989) percebeu a utilização do paradigma indiciário no personagem de Arthur Conan Doyle, Sherlock Holmes, no método do historiador da arte italiano Giovanni Morelli e nas pesquisas de Freud para o desenvolvimento da psicanálise. Nos três casos, argumenta Ginzburg (1989, p. 150), "pistas talvez infinitesimais permitem captar uma realidade mais profunda, de outra forma inatingível. Pistas: mais precisamente, sintomas (no caso de Freud), indícios (no caso de Sherlock Holmes), signos pictóricos (no caso de Morelli)".

Não é surpresa perceber que Ginzburg viu em uma obra literária um dos primeiros exemplos de metáfora e de uso do paradigma indiciário. Além da erudição presente em suas obras e de sua influência familiar, Ginzburg (1990, p. 258) conta que os livros de história talvez não tenham sido as coisas mais importantes que leu e afirma que "os romances foram os livros que mais [o] tocaram". Assim, Ginzburg compreendeu que descobrir o autor de um crime, para Holmes, torna-se um processo de interpretação dos indícios deixados e de atenção aos detalhes imperceptíveis para muitos.

Garnica (1999) comparou Holmes à personagem de Agatha Christie, Miss Marple. Holmes, a partir dos indícios, constrói o quadro de um crime; Miss Marple, ao compreender que "a humanidade resume-se a cópias catalogadas do peixeiro, da criada, da vizinha, do namorado da sobrinha de uma senhora qualquer de St. Mary Mead" (GARNICA, 1999, p. 12), parte de categorias predefinidas para caracterizar qualquer pessoa. Por fim, Garnica (1999)

3 O paradigma indiciário pode, segundo as formas de saber, ser dirigido para a compreensão do passado (na decifração, no caso dos caçadores e na semiótica médica, em sua face diagnóstica, por exemplo), do presente (a política) e do futuro (na adivinhação, no caso dos povos da Mesopotâmia e na semiótica médica, em sua face prognóstica). 
concluiu que as diferenças entre método indutivo e dedutivo de pesquisa ${ }^{4}$ estão presentes nas metáforas de Holmes e Miss Marple, e propõe que pesquisar na área específica da Educação Matemática está associado à postura de Holmes, mais do que à de Miss Marple.

Ginzburg (1989) também percebeu essa postura nos trabalhos de Giovanni Morelli. Com o pseudônimo de Ivan Lermolieff, Morelli desenvolveu um método para identificar cópias de obras de arte: ele percebeu que, para afirmar que um quadro é cópia de outro, há que atentar nas características que dificilmente serão imitadas por outro pintor, "é necessário examinar os pormenores mais negligenciáveis e menos influenciados pelas características da escola a que o pintor pertencia: os lóbulos da orelha, as unhas, as formas dos dedos das mãos e dos pés" (GINZBURG, 1989, p. 144). No momento da pintura de um quadro, esses detalhes constituíam-se em traços puramente individuais, fugiam do controle que o artista conscientemente tinha da tradição cultural e distanciavam-se das características mais vistosas e mais facilmente imitáveis de uma escola. Os pintores que tentavam imitar uma obra de arte se esqueciam dos movimentos mecanizados do artista ao pintar um dedo de um pé, por exemplo. Assim "qualquer museu de arte estudado por Morelli adquire imediatamente o aspecto de um museu criminal" (GINZBURG, 1989, p. 145).

Por sua vez, Morelli foi uma influência intelectual para o pai da psicanálise, Freud. O método morelliano foi "um elemento que contribuiu diretamente para a cristalização da psicanálise" (GINZBURG, 1989, p. 148). A própria psicanálise parte dos pressupostos do paradigma indiciário, ao propor "um método interpretativo centrado sobre os resíduos, sobre os dados marginais, considerados reveladores" (GINZBURG, 1989, p. 149). O caso clínico sobre o homem dos lobos é um dos exemplos analisados por Freud, a partir do método indiciário. Por meio dos sonhos recorrentes com seis ou sete lobos, Freud descobriu as causas da neurose de seu paciente russo de 27 anos.

Porém, Ginzburg (1989) argumenta que Freud não conseguiu perceber os motivos de ser seis ou sete lobos a aparecer no sonho de seu paciente. Dessa forma, Ginzburg retomou os dados de Freud em busca de outros indícios. Ele descobriu que Freud não considerou que seu paciente era originário da Rússia e que nesse país existia uma fábula contada para crianças chamada "O lobo imbecil". A fábula era o indício que faltava para compreender o motivo para o número de lobos. Nesse sentido, Ginzburg (1989) indicou um pressuposto do 
paradigma indiciário não observado por Freud na narrativa desse caso clínico: não se pode ignorar o contexto cultural e considerar apenas a experiência individual.

A partir da atenção dada às pistas, assim como o fizeram Holmes, Morelli e Freud, Ginzburg conseguiu estudar distintas temáticas em suas pesquisas historiográficas. Ao longo de sua vida e para a construção de suas narrativas, ele também foi influenciado pelo marxismo, pela filosofia da linguagem de Bakhtin, pelos historiadores Erick Hobsbawn, Marc Block, Benedetto Croce, Federico Chabod e Delio Cantimori e pelo filósofo italiano Antonio Gramsci.

Ao lidar com pistas e documentos de diferentes tipos, Ginzburg, ao utilizar o paradigma indiciário, encontrou caminhos distintos para chegar sempre ao mesmo objetivo: entender o que as pistas significam e o que os documentos revelam.

Outros paradigmas, como o galileano, têm como pressuposto um caminho seguro a ser percorrido, mesmo que tal caminho não conduza a resultados. Por esse motivo, o rigor do paradigma indiciário é, algumas vezes, questionado. Algumas pesquisas indicam que o paradigma não é fortemente desenvolvido e articulado, como é o caso da pesquisa de Cabrera (2012). Outras afirmam que o paradigma é inconcluso, inacabado e não sistematizado, mas que tem importância epistemológica, este é o caso do estudo de Pimentel e Montenegro (2007). Porém estas duas pesquisas citaram em suas referências apenas o capítulo "Sinais", do livro "Mitos, emblemas e sinais", de Ginzburg (1989).

Ginzburg (1989), por outro lado, argumentou nesse capítulo que disciplinas indiciárias, como a História e a Linguística, por exemplo, não se enquadram nos critérios de cientificidade do paradigma galileano,

[...] a orientação quantitativa e antiantropocêntrica das ciências da natureza a partir de Galileu colocou as ciências humanas num desagradável dilema: ou assumir um estatuto científico frágil para chegar a resultados relevantes, ou assumir um estatuto científico forte para chegar a resultados de pouca relevância (GINZBURG, 1989, p. 178).

Assim, entendo que termos como "paradigma desenvolvido", "conclusivo", "articulado", "acabado" e "sistematizado" estão relacionados e fazem sentido no paradigma galileano, e que a métrica para definir o paradigma indiciário está assentada em outros termos.

Ginzburg (1989, p. 178) entendeu que o rigor do paradigma galileano, por exemplo, "é não só inatingível, mas também indesejável para as formas de saber mais ligadas à experiência cotidiana”. Dessa forma, a fragilidade ou não do paradigma indiciário está ligada aos caminhos escolhidos pelo pesquisador e aos elementos imponderáveis, como o faro, o golpe de vista e a intuição. 
Nesse sentido, o rigor do paradigma indiciário é entendido como flexível. $\mathrm{O}$ rigor se molda ao contexto pesquisado, e "a natureza do problema a ser estudado é que deve determinar as características das proposições, dos processos, das técnicas e dos dispositivos metodológicos utilizados, e não o contrário" (SUASSUNA, 2008, p. 358). Assim, decifrar o problema estudado, para Leonardi e Aguiar (2010, p. 116), "requer um trabalho de 'rigor flexível', que utiliza tanto a rigidez da técnica quanto a fluidez da intuição".

Regras preexistentes e único caminho não existem no paradigma indiciário, mas percebo elementos que o constituem. Em diferentes estudos de Carlo Ginzburg, e não somente no capítulo "Sinais", esses elementos estão dispersos. Busquei, a partir das obras "Mitos, emblemas e sinais" (1989), "Olhos de madeira" (2001), "Nenhuma ilha é uma ilha" (2004), "O queijo e os vermes" (2006), "O fio e os rastros" (2007), "Os andarilhos do bem” (2010), "História noturna" (2012) e "Medo, reverência, terror" (2014), as pistas deixadas por Ginzburg sobre os elementos que constituem o paradigma indiciário, para perceber que contribuições tal paradigma pode dar para a análise de narrativas em pesquisas do campo da Educação.

\section{Contribuições do paradigma para a análise de narrativas: à procura de indícios}

Assim como Carlo Ginzburg procura pistas, ele também deixa pistas. Pistas que me fazem pensar sobre como é possível utilizar o paradigma indiciário e sobre que elementos observar em documentos. Em suas pesquisas, Ginzburg dá indícios sobre maneiras de olhar para eles, sobre o que olhar neles e de que posição olhar.

Os documentos que nos interessam investigar são as narrativas. Portanto, ao analisar narrativas, buscam-se indícios específicos, que denominei de indícios narrativos. Eles se diferenciam, por exemplo, dos indícios materiais encontrados por caçadores, dos signos pictóricos descobertos por Morelli ou das pistas dos crimes encontradas por Holmes. As narrativas trazem um tipo de indício - permeados no enredo e, por conseguinte, narrativos - ligado à história do sujeito. Cabe alertar que há também indícios que não são narrativos, como, por exemplo, os que aparecem em processos de racionalização do sujeito ou no momento da descrição de algo. Todos eles precisam ser levados em conta para compreender e analisar uma narrativa, porém nela a predominância dos narrativos é natural, mesmo que se perceba e se concorde que descrição, narração e racionalização ali caminham juntas. 
Cada narrativa sugere os caminhos a serem seguidos para sua análise, que deve sempre ser flexível, mas essa flexibilidade não impede a atenção para alguns elementos presentes nas narrativas, com o objetivo de encontrar os indícios narrativos ${ }^{5}$.

Assim, Carlo Ginzburg indica os seguintes elementos do paradigma indiciário, os quais entendo que podem ser levados em conta na análise de narrativas:

\section{O órgão do saber indiciário: A firasa}

\section{FIGURA 1 - UM SUFI EM ÊXTASE EM UMA PAISAGEM}

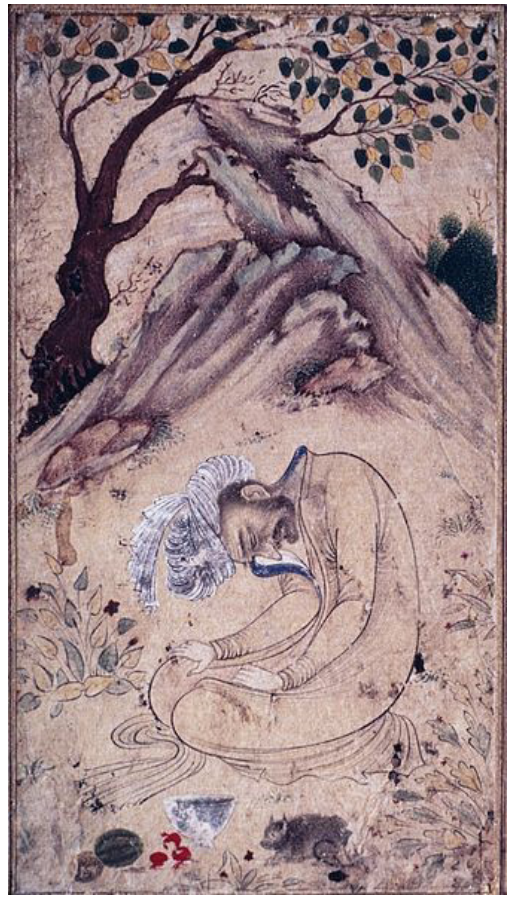

FONTE: Isfahan, século 17. Imagem: Los Angeles County Museum of Art

5 Contudo, não é o objetivo criar um método estruturalista de análise, que focaliza somente em elementos formais (JOVCHELOVITCH; BAUER, 2002), embora, em alguns momentos, tais elementos formais possam auxiliar na identificação de indícios narrativos. 
A firasa ${ }^{6}$ é "a capacidade de passar imediatamente do conhecido para o desconhecido, na base de indícios" (GINZBURG, 1989, p. 179). Designa formas de discernimento, é órgão do saber indiciário para os sufis, uma das correntes do Islã. Para os sufis são necessários a busca por autoconhecimento e um questionamento constante que leve à compreensão do divino. Assim, a firasa possibilita duvidar de si e de tudo.

Estar diante de narrativas e analisá-las relaciona-se com a firasa. É passar do conhecido até aquele momento para o desconhecido que se apresenta nas histórias contadas pelos sujeitos, é duvidar das narrativas, é questionar o que está dito ou escrito, em busca da compreensão. Nesse processo, é necessário surgir a consciência aguda da ignorância do pesquisador (GINZBURG, 2004) e a consciência dos limites do seu próprio conhecimento histórico (GINZBURG, 2012). Pressupõe o despir-se de formulações preconcebidas, o abandonar preconceitos e o buscar pela chave de interpretação (GINZBURG, 1989) a partir dos indícios narrativos deixados. Implica compreender que "a história da humanidade não se desenvolve no campo das ideias, mas sim no mundo sublunar em que os indivíduos, de modo irreversível, nascem, infligem sofrimento ou são a eles submetidos, e morrem" (GINZBURG, 2012, p. 32, grifo meu).

As narrativas utilizadas no campo da Educação se diferenciam das pesquisas desenvolvidas por Ginzburg, na medida em que os sujeitos da investigação são, em grande parte, acessíveis ao pesquisador. Nesse sentido, a firasa opera de maneira distinta. Os testemunhos, em parte das pesquisas com narrativas, são diretos, há acesso aos narradores para procurar outros indícios, perguntar sobre dúvidas e esclarecer parte da história contada. O desconhecido sugere, nesse caso, diálogo. $\mathrm{O}$ desconhecido nas pesquisas de Ginzburg leva à busca por outros documentos históricos, por outras associações que possibilitem observar o sujeito de diferentes miradas, dado que os sujeitos já não vivem no mesmo tempo do pesquisador.

Por outro lado, é possível entender as narrativas como documentos com sujeitos diretos ${ }^{7}$. Ginzburg, quando pesquisou o Sabá e os processos inquisitoriais da Igreja Católica, esteve diante de documentos escritos pelos inquisidores sobre os sujeitos de sua pesquisa, como no caso de Menocchio (GINZBURG, 2006) ou

6 Firasa é a forma traduzida em português na obra de Ginzburg (1989).

7 Há uma diferença entre "testemunho direto" e "documentos com sujeito direto". O primeiro termo se relaciona ao fato de conseguir acesso ao narrador participante da pesquisa (o sujeito da pesquisa é acessível? Ainda está vivo?). O segundo termo se relaciona ao modo como o pesquisador tem acesso à narrativa presente em um documento (a narrativa presente em um documento é feita pelo narrador? Há alguma influência de terceiros no documento e na narrativa ali presente? Há algum intermediário entre narrador e pesquisador?). 
nos casos dos benandanti Gasparutto e Basili (GINZBURG, 2010), por exemplo. Essas narrativas não eram documentos com sujeitos diretos, dado que, entre Ginzburg e os sujeitos de sua pesquisa, existiam intermediários, os inquisidores.

Em todo caso, a documentação variada e heterogênea contribui para a pesquisa na perspectiva do paradigma indiciário. Para Ginzburg (1989, p. 63), "quando os documentos existem, as imagens são lidas em registro psicologizante e 'biográfico'; quando faltam ou não são suficientemente eloquentes, curvase sobre um tipo de 'leitura' mais descritivo e menos interpretativo". Dessa forma, as narrativas, como documentos de sujeitos diretos, proporcionam a compreensão do biográfico; e a firasa opera e parte de indícios narrativos que podem, algumas vezes, ser verificados com os próprios sujeitos da pesquisa por meio de testemunhos diretos.

O que é fundamental é que a fonte seja sui generis, singular (GINZBURG, 1989). No caso das pesquisas com narrativas, os participantes precisam ser pessoas específicas, que indiquem características do objeto de estudo que outra pessoa não indicaria. Diante das narrativas desses sujeitos, é preciso que a firasa opere para que o pesquisador perceba as coisas que costumam ser ocultadas pelo hábito e pela convenção, é preciso espantar-se, estranhar os hábitos, mesmo que se considerem óbvios (GINZBURG, 2001).

A capacidade de passar do conhecido para o desconhecido, a firasa, também está relacionada com a memória, tanto a do pesquisador quanto a do narrador. A memória surge das vivências, estabelece uma relação vital com o passado (GINZBURG, 2001). Enquanto o narrador está entre alusões conscientes a seu passado e lapsos da memória que apontam apego à tradição, o pesquisador busca na memória as suas vivências, que possibilitam perceber o que são as alusões conscientes e o que são lapsos do narrador. É operando dessa maneira com a firasa que Ginzburg (2001) percebe no discurso do Papa João Paulo II, sobre a responsabilização da Igreja Católica pelo antijudaísmo, as alusões conscientes que o Papa queria com seu discurso e os lapsos ligados à tradição que comprometeram o seu discurso. Enquanto, por um lado, o Papa queria dar uma mensagem (alusões conscientes) sobre a responsabilização da Igreja Católica em relação à perseguição aos judeus ao longo dos tempos, por outro, ele tem um lapso de memória ligado à tradição e utiliza uma expressão que sugere que judeus, como irmãos mais velhos dos católicos, são servos dos mais novos (GINZBURG, 2001).

Dessa maneira, Ginzburg dá a pista de que operar com a firasa é perceber que as contradições têm espaço na narração. Os lapsos são ligados às tradições, eles são os geradores das contradições, e percebê-los é compreender o tema da pesquisa.

As características da firasa que identifiquei aqui, como a consciência aguda da ignorância do pesquisador, o despir-se de formulações preconcebidas, 
o abandonar preconceitos, o buscar pela chave de interpretação, o desconhecido que sugere o diálogo, a necessidade de a fonte ser sui generis, o espantar-se, o estranhar os hábitos e a identificação das alusões conscientes e dos lapsos, são alguns dos elementos que se podem observar nas narrativas. Mas não são os únicos...

\section{Elementos imponderáveis: 0 acaso, as sensações, 0 faro, o golpe de vista e a intuição}

No decorrer da análise de narrativas surgem elementos imponderáveis, que podem indicar outros caminhos de interpretação. Pesquisas que assumem uma visão galileana de construção do conhecimento costumam ignorar os elementos imponderáveis, pelo menos no momento de divulgação dos resultados encontrados. Porém, no processo de pesquisa esses elementos estão presentes.

Um primeiro elemento imponderável é o acaso. Pergunto-me: que espaço o acaso assume na pesquisa? Tento reprimi-lo, ao criar justificativas para as ações que faço ao longo da pesquisa? Ginzburg (2004), ao buscar perceber o regime de trocas entre a literatura das ilhas britânicas e a literatura do continente europeu, dá o indício de que "na origem [de seu estudo], há sempre um achado proveniente das margens de investigação inteiramente diversas" (GINZBURG, 2004 , p. 11). Ele informa que foi o acaso que o levou aos comentários de um autor e que, por sua vez, deu início a sua pesquisa.

$\mathrm{O}$ acaso também está presente no processo de análise de narrativas. A própria narrativa pode fazer com que o pesquisador esteja diante de algo que não previa. Súbitas sensações (GINZBURG, 2004) podem indicar as chaves de interpretação, e alguns indícios podem ser encontrados ao acaso, por associações que não foram previstas.

Cabe ao pesquisador, diante do acaso e das suas sensações, recorrer ao seu poder interpretativo e, como Ginzburg, deixar-se "guiar pelo acaso e pela curiosidade, e não por uma estratégia consciente" (GINZBURG, 1989, p. 12). Assim, surgem outros elementos imponderáveis que são o faro, o golpe de vista e a intuição.

Entendo que o faro é a capacidade de perceber chaves de interpretação. Quanto mais afinado o faro de um pesquisador, maior as chances de perceber nas narrativas os indícios que possibilitarão compreender o fenômeno em estudo. A percepção dos indícios não basta por si só, o golpe de vista, ou seja, a maneira de enxergá-los, também é um elemento imponderável ao pesquisador. 
Por fim, há a intuição. Ligada aos sentidos do pesquisador, às experiências e a algo inconsciente. $\mathrm{O}$ funcionamento da intuição não é claro, mas pode indicar caminhos para a análise de narrativas.

Os elementos imponderáveis, o acaso, as sensações, o faro, o golpe de vista e a intuição, se juntam a outros que são ponderáveis - entre eles podemos observar nas narrativas seus elementos estruturais.

\section{Elementos estruturais}

O paradigma indiciário, como modelo epistemológico para interpretação, não é estruturalista. Os elementos formais dos documentos são utilizados por Carlo Ginzburg quando estes são meios para encontrar indícios.

Um primeiro elemento são as palavras e frases prediletas que aparecem nos documentos. Ginzburg (1989) dá indício, no capítulo "Sinais", do livro "Mitos, Emblemas e Sinais", de que perceber a frequência com que tais palavras e frases aparecem nos documentos analisados pode indicar pistas sobre o que se estuda. No referido livro, Ginzburg não se utiliza desse elemento, ou pelo menos não encontrei pistas, mas ele dá indício sobre esse elemento estrutural, ao falar do método morelliano.

Esse elemento estrutural é utilizado em outra obra, "História noturna". Ginzburg (2012) dá indício de procurar perceber a frequência com que palavras e frases aparecem nos documentos, para distinguir a convergência forçada de respostas e perguntas, de inquisidores e investigados, dos diálogos que têm riqueza etnográfica.

Muitas vezes, os acusados, oportunamente guiados pela sugestão ou pela tortura, confessam uma verdade que os juízes não buscavam, dado que já eram dela detentores. A convergência forçada entre as respostas de uns e as perguntas ou expectativas de outros torna grande parte desses documentos monótona e previsível. Só em casos excepcionais verificamos uma diferença entre perguntas e respostas que faz aflorar um substrato cultural substancialmente não contaminado pelos estereótipos dos juízes. Quando isso acontece, a falta de comunicação entre os interlocutores exalta (por um paradoxo apenas aparente) o caráter dialógico dos documentos, assim como sua riqueza etnográfica (GINZBURG, 2012, p. 116, grifos meus). 
Quando os diálogos são ricos, o modo de dizer e a escolha das palavras e frases não são coincidentes para juízes da inquisição e seus acusados. Quando as respostas às perguntas são previsíveis ou utilizam termos que muito provavelmente fazem parte do estrato social dos inquisidores, Ginzburg desconfia de que tais depoimentos foram forjados ou combinados. Pela frequência com que termos aparecem nas perguntas de inquisidores e respostas dos acusados, Ginzburg percebe indícios.

A percepção da frequência de palavras e frases em narrativas em pesquisas em Educação pode dar indícios do que o sujeito compreende sobre um determinado conceito, sobre quais as bases pedagógicas que o guiam e sobre posturas assumidas ao longo da carreira. Utilizar com frequência, nas narrativas, termos como "construção do conhecimento", "transmissão do conhecimento", "aprendizagem significativa", "treinamento", "exercício", "tarefa", "atividade", pode dar indício da perspectiva teórica em que um professor se apoia e revelar se tal perspectiva é consciente, por exemplo. Cabe chamar atenção que a percepção da frequência não objetiva indicar a quantificação de palavras e frases. Não é preciso dizer "o sujeito usou 25 vezes tal expressão". Frequência de palavras e frases, nesse caso, não é fim, mas meio para encontrar alguns indícios narrativos.

Um próximo elemento estrutural a ser observado são os momentos de interrupção, pelo narrador, de sua história para fazer digressões. Ginzburg (2012) deixa indícios de que observou esse elemento estrutural, ao analisar uma página do historiador bizantino Procópio de Cesareia: "De repente, a narrativa [de Procópio] se interrompe para dar lugar a uma digressão, introduzida por palavras cautelosas e solenes [...]" (GINZBURG, 2012, p. 130).

Quando as narrativas são interrompidas pelo narrador, surgem as digressões. Elas podem estar associadas ao desejo de explicar alguma passagem que ele acredite que não ficou clara e aos seus processos de racionalização. Quando uma digressão surge, podem estar presentes indícios (narrativos ou não ${ }^{8}$ ) que indicam medo, receio, angústia, desejo de se explicar, retificação de algum termo que se utilizou de maneira inconsciente ou inconsequente. No caso de Procópio, Ginzburg encontrou um indício de que a digressão foi feita para acrescentar informações de forma cautelosa e solene, antes de prosseguir com sua narrativa.

8 As digressões se apoiam, na maioria dos casos, nas racionalizações. Nesse processo, algumas vezes, a narração se perde. Um ou mais elementos presentes em uma narrativa (temporalidade, espaço físico e contexto) se perdem. Por esse motivo, os indícios presentes nas digressões podem ser narrativos ou não. 
Um próximo elemento estrutural é a etimologia9. Ginzburg (1989, 2001, 2004, 2006, 2007, 2010, 2012, 2014), em diversas pesquisas, utiliza-se de tal elemento para compreender os significados que as palavras assumiam nos contextos históricos pesquisados. Quando algum termo sofre mudanças ao longo do tempo ou aparece em diferentes narrativas de sujeitos em tempos e/ou espaços distintos, Ginzburg recorre à etimologia. Algumas vezes ela dá indícios dos motivos de uma expressão ser usada por diferentes sujeitos, em distintos lugares ou em épocas diferentes.

A investigação da origem e do desenvolvimento dos significados das palavras parte do pressuposto de que a

continuidade de palavras não significa necessariamente continuidade de significados. O que chamamos de "filosofia" ainda é, apesar de tudo, a "filosofia" dos gregos; já a nossa "economia" - tanto a disciplina como seu objeto - e a "economia" dos gregos têm pouco ou nada em comum (GINZBURG, 2001, p. 42).

Ao analisar as narrativas de diferentes sujeitos, podem-se perceber palavras comuns, mas com significados e sentidos distintos; a etimologia pode dar indícios de qual dos significados/sentidos de uma palavra o narrador está utilizando. Por exemplo, quando utiliza a palavra "atividade", caso o narrador conheça a Teoria da Atividade de Alexei Leontiev, terá um significado; caso desconheça, terá outro sentido.

Atrelado à etimologia, Ginzburg recorre à reconstrução analítica dos elementos geográficos e cronológicos presentes nos documentos. Essa reconstrução é mais um elemento estrutural de documentos e narrativas. Carlo Ginzburg (2012) reconstrói a geografia e a cronologia para perceber indícios de como surgem os discursos no continente europeu que associam os judeus como os culpados pela peste negra, por exemplo. A cronologia dos fatos mostrou para Ginzburg como o discurso foi se proliferando por toda a Europa por pressões de baixo (da população) e intervenções do alto (das autoridades) ao longo do tempo, enquanto a geografia indicou os locais em que esse discurso foi se consolidando e se transformando em violência. A cronologia pode contribuir para a percepção de elementos temporais e atemporais nas narrativas.

9 Etimologia é o campo que se dedica a estudar a origem das palavras e a história dos seus significados. 
Observar elementos temporais e atemporais em documentos e narrativas também é uma preocupação de Carlo Ginzburg, ao utilizar o paradigma indiciário. O que permanece, o que muda e o que não depende da variável tempo são as questões que percorrem seus estudos. As relações entre presente, passado e futuro se revelam, ao perceber tais elementos. Ginzburg (2012) dá indícios de buscar compreender elementos temporais e atemporais, ao refazer o percurso de constituição do Sabá, por exemplo. Ele inicia a apresentação do seu estudo por um andamento narrativo linear, cronológico e vai identificando as mudanças na visão sobre o Sabá ao longo do tempo e as permanências de entendimento sobre ele. Posteriormente, ao ter compreensão sobre o desenvolvimento do Sabá e sobre seus elementos temporais e atemporais, Ginzburg abandona o fio narrativo que seguia e ignora sucessões cronológicas, "na tentativa de reconstruir por meio de afinidades algumas configurações míticas e rituais, documentadas num espaço de milênios, por vezes a milhares e milhares de quilômetros de distância" (GINZBURG, 2012, p. 26).

No processo de análise de narrativas, a reconstrução analítica da geografia e da cronologia pode auxiliar o pesquisador a compreender os movimentos de mudança - tanto de localidade quanto de pensamento - do narrador e pode também dar indícios dos momentos em que a vida sofreu reveses.

Para além dos elementos estruturais, como a frequência de utilização de palavras e frases, as digressões, a etimologia, a geografia e a cronologia - pela identificação de elementos temporais e atemporais -, há outros, atrelados à postura do pesquisador diante de uma narrativa que será analisada. Vamos a eles...

\section{Para uma visão não insular: ponto de vista e perspectiva}

Como disse, no livro “O queijo e os vermes", Carlo Ginzburg (2006) cria sua narrativa a partir do mundo visto por um moleiro. Ao agir dessa forma, ele revela a postura que o pesquisador precisa ter, ao contar a história de outro sujeito, qual ponto de vista privilegiar: o do pesquisador, o do inquisidor ou do moleiro Menocchio. É possível assumir qualquer um desses pontos de vista, a depender do que se escolhe contar e da maneira como se conta. Ginzburg consegue diferenciar, ao longo do seu texto, esses pontos de vista, tecendo uma narrativa que vai indicando de que ponto de vista se observa.

O ponto de vista é um elemento a ser considerado para que a história a ser contada se aproxime da maneira com que o narrador contou. Por essa razão, defendo que em pesquisas da área da Educação é interessante apresentar as 
narrativas dos sujeitos em um primeiro momento, com a consciência de que o pesquisador buscará apenas o enredamento das histórias contadas para dar coerência e sentido. É importante que nesse momento o pesquisador suspenda suas análises e conte a história, buscando manter o ponto de vista do narrador. É possível que a narrativa do sujeito e a análise caminhem juntas, como o faz Ginzburg em suas pesquisas, mas compreendo que a separação auxilia o pesquisador a tomar consciência de qual ponto de vista está presente, o seu ou o do narrador. A fase de análise e da procura pelo entendimento do objeto de pesquisa pode ser apresentada em um segundo momento, em que aparece com mais clareza e intencionalidade o ponto de vista do pesquisador.

Para esse segundo momento, Ginzburg sinaliza que o olhar do pesquisador precisa ser atravessado por outras formas de ponto de vista, o cronológico, o espacial/geográfico, o cultural, o morfológico-etimológico e o temático (GINZBURG, 2012). Já disse que a geografia, a cronologia e a etimologia são elementos estruturais nas narrativas, mas também são constituintes do ponto de vista assumido pelo pesquisador. Acrescenta-se a esses elementos o ponto de vista temático e cultural.

Ao analisar narrativas, o pesquisador pode encontrar temas comuns entre elas. O ponto de vista temático pode mostrar indícios das recorrências e de como elas se apresentam em diferentes trajetórias de vida.

Por outro lado, o ponto de vista sobre a cultura de uma época pode dar pistas sobre os motivos de o narrador ter dito algo e sobre a maneira como foi dito. Narrar e descrever são atividades irmãs, em minha percepção. Para descrever, o pesquisador precisa de um ponto de vista cultural. É pela descrição que ele consegue mostrar ao leitor os contextos em que as tramas se desenvolveram ou as características do narrador, para compreender a história contada. É nesse sentido que a descrição deve ser culturalmente condicionada (GINZBURG, 2012). É a partir de um ponto de vista cultural que Ginzburg descreve um pente de cabelo em seus mínimos detalhes no livro "História noturna", por exemplo.

A cultura também é um ponto de vista necessário na análise de narrativas, devido a sua circulação e circularidade. Para Carlo Ginzburg (2006), existe um relacionamento circular entre as diferentes culturas. No caso da Europa pré-industrial, ele percebeu que a cultura das classes dominantes e das classes subalternas faziam mútuas trocas (circularidade cultural), e essa circularidade se manifestou pela linguagem (SILVA, 2017). Ela também se manifesta nas narrativas. Nas narrativas docentes, por exemplo, aparecem aspectos culturais comuns a professores de distintas localidades, de distintas classes e que estão em diferentes fases da carreira. 
Esses diferentes pontos de vista auxiliam a análise e podem ajudar o pesquisador a perceber as narrativas de uma visão não insular. Quando Ginzburg (2004, p. 113) compreendeu que a literatura inglesa se desenvolveu, entre outras coisas, a partir de trocas com a literatura do resto do continente europeu, ele percebeu também que "nenhum homem é uma ilha, nenhuma ilha é uma ilha". Ginzburg (2004) dá indícios de que documentos e narrativas não podem ser considerados como ilhas. A experiência do narrador aconteceu com os outros, não sozinho, ocorreu por meio de trocas, e por isso não é possível fixar o olhar apenas no sujeito, sem perceber o que está ao redor e como o redor se relaciona com o sujeito.

Perceber trocas pressupõe, além dos diferentes pontos de vista, uma perspectiva de longa duração. Ginzburg (2001) usa, em suas pesquisas, perspectivas de longa duração que abrangem séculos e, às vezes, milênios. Em pesquisas com narrativas na área da Educação, a longa duração pode ser o percurso de uma vida.

É a perspectiva que faz surgir a tensão entre ponto de vista subjetivo e verdades objetivas. Para Ginzburg (2001, p. 198), a perspectiva pode ser lugar de encontro, "uma praça onde se pode conversar, discutir e dissentir". A perspectiva de longa duração contribui para essa tensão e torna-se um local de encontro onde o fenômeno em estudo poderá ser compreendido em suas múltiplas facetas e mudanças.

Para além dos diferentes pontos de vista discutidos até aqui, como os pontos de vista de sujeitos (narrador, pesquisador etc.) ou os pontos cronológico, espacial e geográfico, cultural, morfológico-etimológico e temático e da perspectiva de longa duração, Ginzburg também faz pensar sobre as questões referentes à distância e à proximidade durante $\mathrm{a}$ análise de narrativas. Não basta para o pesquisador ter consciência somente da maneira como irá olhar, mas também da distância com que se olha.

Olhar a ilha da ilha? Olhá-la do continente? Ou olhá-la no meio do caminho? Vamos a estes elementos.

\section{A proximidade e a distância}

Quão distante ou quão próximo devo estar do objeto de pesquisa? E dos sujeitos das pesquisas? Por que questões de distância e proximidade são elementos importantes na busca de indícios? 
Carlo Ginzburg (2001) retoma uma história de Chateaubriand sobre o dilema ético de matar um mandarim chinês. Nessa história, dois amigos europeus conversam, e um deles questiona o outro se ele mataria um mandarim chinês para ficar rico. A morte não seria descoberta por ninguém e poderia ser feita como mágica: com um balanço de cabeça. O mandarim, além de estar muito distante espacialmente dos dois amigos, está distante como humano, pertencente a uma outra dinâmica de valores culturais.

A partir dessa história, Ginzburg (2001, p. 13) faz pensar que o excesso de distância cria a indiferença e "a ausência de empatia como desumanização", e a proximidade excessiva pode "desencadear a compaixão ou uma rivalidade aniquiladora" (GINZBURG, 2001, p. 203). Por outro lado, uma distância justa, crítica, cria estranhamento - modo de atingir as coisas e de "libertar-se de ideias e representações falsas" (GINZBURG, 2001, p. 34). Para Ginzburg (2001), o estranhamento cria também ausência de empatia, mas como distância crítica.

Se a distância justa e o estranhamento são elementos que auxiliam a identificar indícios, a proximidade, a familiaridade com o que se pesquisa pode ser um problema:

Compreendi melhor algo que já pensava saber, isto é, que a familiaridade, ligada em última análise à pertença cultural, não pode ser um critério de relevância. "O mundo todo é a nossa casa" não quer dizer que tudo seja igual; quer dizer que todos nos sentimos estrangeiros em relação a alguma coisa e a alguém (GINZBURG, 2001, p. 11).

É o excedente de visão, a exotopia (BAKHTIN, 1997) que possibilita sentirmo-nos estrangeiros a algo ou alguém, por que é pela exotopia que exercitamos o sair de si, o enxergar-se de fora, como um estrangeiro.

Ginzburg (2001) deixa indícios de que a escrita também contribui para criar uma distância crítica. Foi por meio da escrita que Platão criou uma distância em relação aos mitos arraigados nas culturas orais e pôde analisá-los. A distância justa criada entre oralidade e escrita fez com que ele compreendesse os mitos (GINZBURG, 2001). No caso das narrativas orais em pesquisas do campo da Educação, a textualização pode ajudar a criar tal distância, pois analisar a fala é um processo diferente de analisar cada parte de um texto escrito, cada palavra empregada, cada conjugação usada. Pela fala podem surgir distanciamentos de detalhes e miudezas que são indícios importantes para compreender o que se investiga. Pela textualização pode-se retomar essa aproximação que cria uma distância justa. 
A proximidade, a familiaridade, por sua vez, pode não ser problemática, se ela auxiliar a identificar indícios somente visíveis pela proximidade do pesquisador com seu objeto ou sujeito participante da pesquisa. Nesse caso, é uma proximidade justa. Isso faz sentido, pois "a tendência a apagar os traços individuais de um objeto é diretamente proporcional à distância emocional do observador" (GINZBURG, 1989, p. 163). Chineses podem parecer iguais para brasileiros (distantes deles espacial e culturalmente), mas, para os próprios chineses (próximos espacial e culturalmente), eles não o são. Professores podem parecer iguais para sujeitos não relacionados à área da Educação, porém, para formadores de professores, não o são.

Ginzburg (2001) também dá indícios de que não há somente um tipo de distância. Existe a distância espacial, como na história do mandarim chinês, mas também existe a distância temporal. Criar uma distância justa entre o passado e o presente é uma tarefa que Ginzburg busca em suas pesquisas, ao utilizar o paradigma indiciário, pois, se não o fizesse, o passado seria analisado com os olhos distantes do presente. A consciência da distância temporal entre presente e passado é um elemento que guia Carlo Ginzburg. Em pesquisas com narrativas, pensar na distância temporal também se faz necessário. O sujeito de hoje não foi o sujeito de ontem; o professor experiente hoje já foi iniciante, seus pensamentos e ações eram outros, por exemplo.

A distância justa não é causadora de apatia, muito menos de antipatia. Ausência de empatia como distância crítica não quer dizer que o olhar do pesquisador não possa ser apaixonado. Quando olhamos as narrativas e seus narradores como adivinhas, está (ou deveria estar) presente um olhar distante e ao mesmo tempo apaixonado. Paixão e distância caminham juntas para criar estranhamento.

Por sua vez, o estranhamento é, em primeiro lugar, um procedimento literário, como no conto "Kholstomer", de Tolstoi, em que um cavalo narra a história e faz considerações sobre a cultura humana ou em "As aventuras de Pinocchio", de Carlo Collodi, em que um boneco de madeira se torna menino e se aventura por um mundo então desconhecido. Tanto o olhar do cavalo como o de Pinocchio são criados por esse procedimento literário. Porém, mais que um processo literário, ele é "um antídoto eficaz contra um risco a que todos nós estamos expostos: o de banalizar a realidade (inclusive nós mesmos)" (GINZBURG, 2001, p. 41). O estranhamento é "uma tentativa de apresentar as coisas como se vistas pela primeira vez" (p. 37), mas não pode ser utilizado como expediente deslegitimador. Estranhar é para compreender, não para afirmar que o que vejo é diferente do que acredito e discorrer sobre meus juízos de valor. 
Distância e proximidade justas, em suas múltiplas facetas (temporal e espacial), olhar apaixonado e estranhamento são elementos do paradigma indiciário que contribuem para que o pesquisador em Educação possa perceber indícios narrativos. Mas também não são os únicos, e Ginzburg dá indícios de outros. Continuo o diálogo...

\section{Elementos isomorfos: fios de um mesmo tecido}

Como "nenhum homem é uma ilha" (GINZBURG, 2004, p. 113), existem nas narrativas elementos que os homens criam e são isomorfos. O conceito de isomorfia está relacionado às características que dois objetos têm em comum. Ginzburg utiliza o conceito de isomorfismo no sentido mais de semelhança do que de igualdade. Ele deixa indícios desse modo de utilização, ao argumentar que procurará, ao buscar compreender os rituais fúnebres de reis franceses e ingleses, "demonstrar [que] as semelhanças transculturais podem ajudar a compreender a especificidade dos fenômenos de que partiram" (GINZBURG, 2001, p. 87).

Dessa maneira, Ginzburg (2012, p. 198), ao pesquisar as relações entre mitos e ritos, informa que "em vez de coincidências falaremos de isomorfismos, mais ou menos parciais" Para ele, os isomorfismos podem indicar um núcleo narrativo comum e os paralelismos múltiplos podem colocar "questões mais importantes" (GINZBURG, 2012, p. 253).

Os elementos isomorfos permitem-nos pensar em documentos ou narrativas como fios que combinam no mesmo tecido, como Ginzburg (2012) dá indícios no livro Histórias noturnas, ou entendê-los como peças de um mosaico, como há indícios no livro "Os andarilhos do bem" (GINZBURG, 2010).

São os isomorfismos que possibilitam inserir as produções dos participantes da pesquisa em um contexto mais amplo (GINZBURG, 2004) e identificar uma rede de semelhanças (GINZBURG, 2012), pois é por eles que surgem as ideias e as ações comumente presentes em diversos indivíduos de um grupo social.

Perceber a isomorfia como elemento para encontrar indícios narrativos só é possível ao entender a identidade em suas conexões com a alteridade (GINZBURG, 2004). Analisar narrativas pressupõe entender que o narrador se configura como sujeito social que interage com os outros e é interdependente desses.

Por outro ponto de vista, Ginzburg (2012) sinaliza que é preciso cautela em relação aos elementos isomorfos. Sem cautela e cuidado, eles podem fazer com que a homogeneidade de alguns dados dê a impressão de que os contextos também são homogêneos, e não heterogêneos. No livro "Os andarilhos do bem", Ginzburg (2010, p. 16) dá outra pista sobre a questão do isomorfismo: 
Insistindo nos elementos comuns, homogêneos, de mentalidade de um certo período, somos inevitavelmente induzidos a negligenciar as divergências e os contrastes entre as mentalidades das várias classes, dos vários grupos sociais mergulhando tudo numa "mentalidade coletiva" indiferenciada e interclassista. Desse modo, a homogeneidade - de resto sempre parcial - da cultura de uma determinada sociedade é vista como ponto de partida e não como ponto de chegada.

Os elementos isomorfos são pontos de partida para encontrar indícios narrativos. E esses levarão ao ponto de chegada, que é a compreensão do fenômeno em estudo.

Identificar isomorfismos é possível não somente pela linguagem verbal, mas também em formas de linguagem não verbal, como as obras de arte, por exemplo. As obras de arte, as fotografias, as esculturas, os mapas etc. são, por sua vez, elementos imagéticos que também podem dar indícios narrativos sobre o fenômeno que se estuda. Passo agora para a compreensão dos elementos imagéticos no paradigma indiciário.

\section{Elementos imagéticos}

Imagens, como documentos não verbais, também contam histórias, ou melhor: possibilitam que histórias sejam contadas. Pinturas, esculturas, fotografias, charges, cenas de um filme etc. são testemunhos figurativos, e podemos utilizá-los como fontes históricas. Porém, Carlo Ginzburg (1989) adverte que uma imagem é mais ambígua quando comparada a uma declaração verbal e não pode ser interpretada sem levar em conta o contexto em que foi produzida.

Ao longo de suas pesquisas, Ginzburg costuma utilizar pinturas, mapas, esculturas, capas de livros, cartazes, anúncios e fotografias. O livro "Medo, reverência, terror" (2014) é uma de suas obras em que os elementos imagéticos assumem centralidade: Ginzburg utiliza diferentes tipos de imagens para compreender como a política se manifesta na arte.

Ginzburg (1989, p. 62), ao citar a obra do historiador da arte Fritz Saxl, já tinha dado indícios de que entendia que a obra de arte é "uma reação complexa e ativa (sui generis, bem entendido) aos acontecimentos da história circundante". Porém, é em Medo, reverência, terror (2014) que Ginzburg deixa claro que compreende os elementos imagéticos dessa maneira, ao estudar a iconografia política. 
Em entrevistas que geram narrativas- em que as imagens estão em movimento ao longo da entrevista -, por exemplo, pode ser que a figura do entrevistado e suas expressões indiciem sentimentos, pensamentos e sensações que não estão sendo expressos em linguagem verbal. Ginzburg (2004) aponta que em narrativas, algumas vezes, as associações visuais podem contradizer a perspectiva auditiva. Caso as entrevistas sejam videogravadas, é possível retomar os frames para perceber um riso ao mesmo tempo em que o olhar está triste, uma emoção, um gesto com as mãos ou outras partes do corpo ou uma postura corporal ao longo de um momento de silêncio.

Imagens, como objetos (fotografias de um álbum sobre a infância, por exemplo), são portadoras de significado (GINZBURG, 2001). Entendo que, caso o pesquisador tenha acesso às fotografias dos participantes da pesquisa, é interessante incluí-las na narrativa, pois elas têm duplo papel: auxiliam a humanizar as pessoas em uma narrativa e acrescentam informações que extrapolam a capacidade da linguagem verbal.

Imagens, como representações dos objetos (uma fotografia que foca a lancheira e a mochila de uma criança em seu primeiro dia na escola, por exemplo), são afirmativas. No exemplo, é possível afirmar que há uma lancheira, ela é de um determinado tamanho, tem uma cor, a criança segura-a de tal forma. Porém é preciso da linguagem verbal para ter acesso à memória afetiva que a pessoa tem sobre aquela lancheira e sobre o que costumava conter que a faz ter tal memória. "As imagens, quer representem objetos existentes, inexistentes ou objeto nenhum, são sempre afirmativas. Para dizer Ceci n'est pas une pipe [Isto não é um cachimbo], necessitamos de palavras (ilustração 19). As imagens são o que são" (GINZBURG, 2001, p. 138).

A ilustração a que Ginzburg se refere é o quadro de René Magritte:

FIGURA 2 - A TRAIÇÃO DAS IMAGENS. 1929

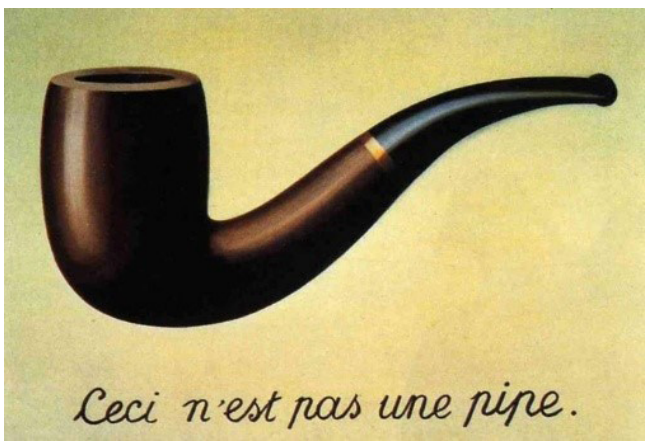

FONTE: Carlo Ginzburg (2001, p. 138). 
Pelas razões expostas acima, entendemos que os elementos imagéticos contribuem para encontrar indícios narrativos. As imagens auxiliam a contar uma história de vida e a compreendê-la.

\section{Considerações finais}

Em uma entrevista às professoras Alzira Alves de Abreu, Ângela de Castro Gomes e Lucia Lippi Oliveira, Ginzburg (1990, p. 255) narra:

Ao iniciar meus estudos na Scuola Normale, em Pisa, pensava em trabalhar com história da literatura, tornar-me um literato. E havia um seminário de um professor que ensinava em Florença chamado Delio Cantimori, um dos historiadores mais importantes da Itália. Ele ia passar uma semana em Pisa, e disse que iria ler e comentar a obra de Burckhardt, Considerações sobre a história do mundo. Lembro-me muito bem do momento em que o vi pela primeira vez: era um homem gordo, não muito alto, de barba branca, com uma cara de cardeal, como nos retratos de cardeais de El Greco. Falava com uma voz pastosa, e perguntou: "Algum de vocês lê alemão?". Muito poucos liam. Ele continuou: "Bom, vamos ler o livro de Burckhardt, mas vamos comparar as traduções italiana, francesa, inglesa etc." Começamos, e depois de uma semana tínhamos lido cerca de dez linhas. Aquilo me marcou profundamente. Aquela maneira de ler o texto levantando uma multiplicidade de problemas foi algo que me pareceu realmente magnífico.

A análise de narrativas também precisa de uma leitura cuidadosa. Entendo que essa leitura cuidadosa passa por perceber os elementos discutidos aqui (Figura 3). 


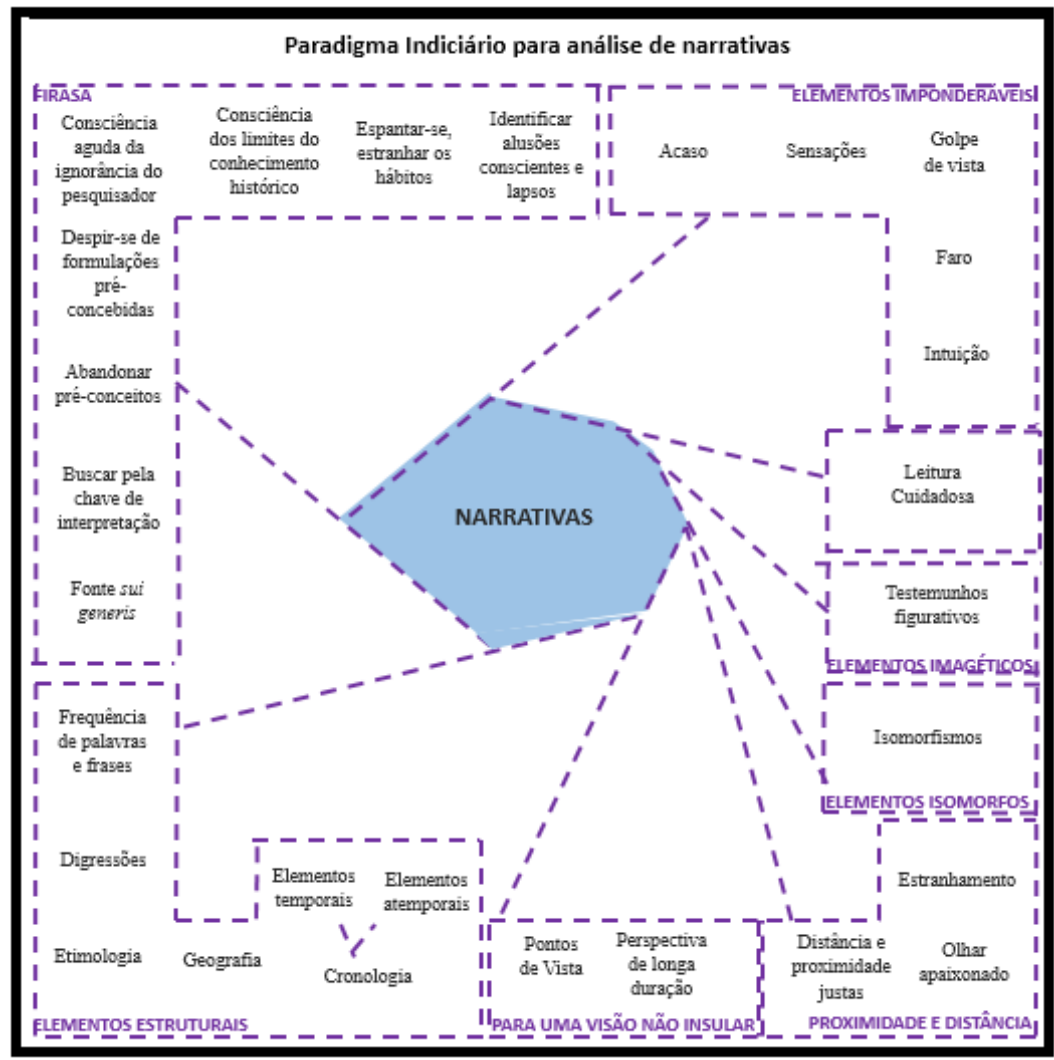

FONTE: elaboração do pesquisador.

Encontrar indícios narrativos e utilizar o paradigma indiciário em uma pesquisa exige cuidado. Neste artigo, ao buscar apresentar contribuições do paradigma indiciário para análise de narrativas em pesquisas do campo da Educação, encontrei uma multiplicidade de elementos que podem auxiliar os pesquisadores durante essa tarefa.

Ginzburg deixou muitas pistas em suas produções, e cada pesquisador que se debruçar nas produções desse historiador italiano poderá encontrá-las. Eu encontrei algumas. $\mathrm{O}$ fato é: pude perceber a riqueza do paradigma indiciário para o desenvolvimento de pesquisas que assumem as narrativas como documentos para compreender fenômenos educacionais. 


\section{REFERÊNCIAS}

BAKHTIN, Mikhail. Estética da criação verbal. São Paulo: Martins Fontes, 1997.

BOLÍVAR, Antônio; DOMINGO, Jesús; FERNÁNDEZ, Manuel. La investigación biográfica-narrativa en educación: enfoque y metodologia. Madrid: La Muralia, 2001.

BURNS, Edward M. História da civilização ocidental: do homem das cavernas até a bomba atômica - O drama da raça humana. Porto Alegre: Globo. 1972.

CABRERA, Mônica A. O paradigma indiciário e as representações sociais dos professores dos anos iniciais do Ensino Fundamental acerca de seu papel. In: ENCONTRO DE ENSINO, PESQUISA E EXTENSÃO DA UNOESTE, 17., 2012, Presidente Prudente. Anais eletrônicos [...]. Presidente Prudente: Unoeste, 2012. Disponível em: http:/www.unoeste.br/site/enepe/2012/suplementos/area/Humanarum/ Ci\%C3\%AAncias\%20Humanas/Educa\%C3\%A7\%C3\%A3o/O\%20PARADIGMA\%20 $\% 20$ INDICI $\%$ C3\%81RIO $\% 20$ E $\% 20$ AS $\% 20$ REPRESENTA $\%$ C3\%87\%C3\%95ES\%20 SOCIAIS $\% 20$ DOS $\% 20$ PROFESSOR $\% 20$ ES $\% 20$ DOS $\% 20$ ANOS $\% 20$ INICIAIS $\% 20$ DO\%20ENSINO\%20FUNDAMENTAL\%20ACERCA\%20DE\%20SEU\%20PAPEL. pdf. Acesso em: maio 2020. Tema: Universidade sem fronteira: da fragmentação a totalidade.

COELHO, Ana Luíza F. O paradigma indiciário como metodologia para estudos historiográficos. In: FÓRUM ENSINO, PESQUISA, EXTENSÃO, GESTÃO, 8., 2014, Montes Claros, MG. Anais eletrônicos [...]. Monte Claros, MG: Unimontes, 2014. Disponível em: http://www.fepeg2014.unimontes.br/sites/default/files/resumos/arquivo_ pdf_anais/o_paradigma_indiciario_como_metodologia_para_estudos_historiograficos. pdf. Acesso em: 15 ago. 2018. Tema: Universidades: saberes e práticas inovadoras.

GARNICA, Antonio Vicente M. Filosofia da educação matemática: algumas ressignificações e uma proposta de pesquisa. In: BICUDO, Maria Aparecida V. (ed.). Pesquisa em educação matemática: concepções e perspectivas. São Paulo: Editora UNESP, 1999.

GIOVANI, Fabiana; SOUZA, Nathan B. Bakhtin e a Educação: a ética, a estética e a cognição. São Carlos: Pedro e João Editores, 2014.

GINZBURG, Carlo. Mitos, emblemas e sinais: morfologia e história. Tradução de Federico Carotti. São Paulo: Companhia das Letras, 1989.

GINZBURG, Carlo. História e cultura: conversa com Carlo Ginzburg. Estudos Históricos, Rio de Janeiro, v. 3, n. 6, p. 254-263, 1990. Disponível em: http://nei.ufes.br/sites/nei. ufes.br/files/Hist $\%$ C3\%B3ria\%20e\%20cultura_Conversa $\% 20$ com\%20Ginzburg.pdf. Acesso em: 13 jun. 2019.

GINZBURG, Carlo. Descobertas de um espectador. Entrevista cedida a Maria Lúcia G. Pallares-Burke. Folha de São Paulo, São Paulo, jun. 1999. Disponível em: https:// www1.folha.uol.com.br/fsp/mais/fs13069912.htm. Acesso em: 15 ago. 2018. 
GINZBURG, Carlo. Olhos de madeira: nove reflexões sobre a distância. São Paulo: Companhia das Letras, 2001.

GINZBURG, Carlo. Nenhuma ilha é uma ilha: quatro visões da literatura inglesa. São Paulo: Companhia das Letras, 2004.

GINZBURG, Carlo. O queijo e os vermes: O cotidiano e as ideias de um moleiro perseguido pela Inquisição. São Paulo: Companhia das Letras, 2006.

GINZBURG, Carlo. O fio e os rastros: verdadeiro, falso, fictício. São Paulo: Companhia das Letras, 2007.

GINZBURG, Carlo. Os Andarilhos do bem: feitiçaria e cultos agrários nos séculos XVI e XVII. São Paulo: Companhia das Letras, 2010.

GINZBURG, Carlo. História noturna: decifrando o sabá. São Paulo: Companhia das Letras, 2012.

GINZBURG, Carlo. Medo, reverência, terror: quatro ensaios de iconografia política. São Paulo: Companhia das Letras, 2014.

GOMES, Emanuelle Garcia. O símbolo dos olhos através do "paradigma indiciário" de Carlo Ginzburg. Revista Espaço Acadêmico, Maringá, n. 193, jun. 2017. Disponível em: http://www.periodicos.uem.br/ojs/index.php/EspacoAcademico/article/ view/33414/19457. Acesso em: 25 jun. 2019.

JOVCHELOVITCH, Sandra; BAUER, Martin W. Entrevista narrativa. In: BAUER, Martin W.; GASKELL, George. Pesquisa qualitativa com texto, imagem e som. Tradução de Pedrinho Guareschi. Petrópolis: Vozes, 2002.

LEONARDI, Paula; AGUIAR, Thiago B. As potencialidades para o uso da obra de Carlo Ginzburg na História da Educação. Revista Tempos e Espaços em Educação, São Cristovão, SE, v. 5, p. 107-123, jul./dez. 2010. Disponível em: https://seer.ufs.br/index. php/revtee/article/view/2231/1902. Acesso em: 13 jun. 2019.

NACARATO, Adair M.; PASSOS, Cármen L. B.; SILVA, Heloisa. Narrativas na pesquisa em Educação Matemática: caleidoscópio teórico e metodológico. Bolema, Rio Claro, SP, v. 28, n. 49, ago. 2014. Disponível em: http://www.scielo.br/scielo.php?script=sci arttext\&pid=S0103-636X2014000200701. Acesso em: 20 maio 2019.

PIMENTEL, Edna F.; MONTEGRO, Zilda M. C. Aproximações do paradigma indiciário com o pensamento freiriano: uma construção possível? Práxis Educacional, Vitória da Conquista, n. 3, p. 181-194, 2007. Disponível em: http://www.periodicos.uesb.br/index. php/praxis/article/view/355. Acesso em: 13 jun. 2019.

SILVA, Leonardo S. da. Carlo Ginzburg: O conceito de circularidade cultural e sua aplicação nos estudos sobre a Música Popular Brasileira. Revista Augustus, Rio de Janeiro, v. 22, n. 43, jan./jun. de 2017. Disponível em: http://apl.unisuam.edu.br/revistas/index. php/revistaaugustus/article/view/19811896.2017v22n43p72. Acesso em: 10 jun. 2019. 
SUASSUNA, Lívia. Pesquisa qualitativa em Educação e Linguagens: histórico e validação do paradigma indiciário. Perspectiva, Florianópolis, v. 26, n. 1, p. 341-377, jan./jun. 2008. Disponível em: https://periodicos.ufsc.br/index.php/perspectiva/article/ view/2175- 795x.2008v26n1p341. Acesso em: 13 jun. 2019.

Texto recebido em 20/06/2020.

Texto aprovado em 26/08/2020. 